\title{
PVT Measurements, Virial Coefficients, and Joule-Thomson Inversion Curve of Fluorine*
}

\author{
Rolf Prydz** and G. C. Straty** \\ Institute for Basic Standards, National Bureau of Standards, Boulder, Colorado $\mathbf{8 0 3 0 2}$
}

(June 1, 1970)

\begin{abstract}
Experimental $P V T$ measurements on gaseous and liquid fluorine from the triple point $(53.5 \mathrm{~K})$ to $300 \mathrm{~K}$ at pressures to about $21 \mathrm{MN} / \mathrm{m}^{2}$ are presented. The data are represented by a truncated virial equation in the low-density region. Comparisons of the second virial coefficient from this equation are made with published data. The PVT relationship along the Joule-Thomson inversion curve was obtained from the isotherm-isochore representation of the high density region.
\end{abstract}

Key words: Isochores; isotherms; Joule-Thomson inversion curve; liquid densities along melting line; PVT data; second virial coefficient; third virial coefficient.

\section{Introduction}

This laboratory is currently engaged in a comprehensive program to determine the thermodynamic and transport properties of compressed liquid and gaseous fluorine. Extensive, precise, PVT data are essential to the calculation of thermodynamic functions required for engineering development of proposed rocket propulsion systems. Since fluorine is not only the most reactive of all elements but also extremely toxic, it is not surprising that physical properties data on this fluid have either been inconsistent or, in many cases, nonexistent. Recently, however, some thermodynamic data have been reported by the authors of this paper $[1,2,3] .{ }^{1}$ The equations representing these data are given in the appendix of this paper for the sake of completeness.

It is the purpose of this paper to report new experimental $P V T$ data from the triple point $(53.5 \mathrm{~K})$ to $300 \mathrm{~K}$ for pressures to a maximum of $21 \mathrm{MN} / \mathrm{m}^{2}\left(1 \mathrm{MN} / \mathrm{m}^{2}\right.$ $=9.86923 \mathrm{~atm})$. Also reported are derived values for the second and third virial coefficients and the JouleThomson inversion curve.

\section{PVT Measurements}

The experimental apparatus and instrumentation used for the PVT measurements on fluorine have been described earlier [4]. To measure single-phase densities, the common gas expansion method was used. After filling and closing off the sample holder, a sequence of pressure-temperature observations were

\footnotetext{
*This work was carried out at the National Bureau of Standards under the sponsorship of the United States Air Force (MIPR No. FO 4611-70-X-0001)

**Cryogenies Division, National Bureau of Standards Laboratories, Boulder, Colo. 80302

${ }^{1}$ Figures in brackets indicate the literature references at the end of this paper.
}

made on the nearly constant density fluid confined in the PVT cell whose volume was accurately calibrated. Temperatures were regulated at integral values (on IPTS 1948 and the NBS 1955 temperature scale) to permit analysis of the data along isotherms. The temperatures of table 1, however, were converted to IPTS 1968 using the temperature scale differences given by references $[5,6]$. When either maximum pressure $\left(21 \mathrm{MN} / \mathrm{m}^{2}\right)$ er maximum temperature $(300 \mathrm{~K})$ was reached, the fluorine sample in the $P V T$ cell was expanded into large calibrated volumes maintained near room temperature. The density could then be determined since the volume of the sample holder and the compressibility factor, $P V \mid R T$, of fluorine gas at the conditions in the expansion volumes were known. This fluorine compressibility factor was obtained using Burnett [7] gas expansion techniques. The results of all volume calibrations necessary for the density determination and the Burnett expansion experiment may be obtained from reference [8].

All experimental single-phase $P V T$ data in both the compressed liquid and vapor regions are given in table 1. The column of this table labeled "IDENT" contains the identification number of each data point. The last two digits represent the point number while the remaining digits are the number of the run or experimental isochore. Entries in runs 120 and 121 which contain no value for the density are pressures measured on the melting curve. Experimental PVT data for densities less than $0.22 \mathrm{~mol} / \mathrm{l}$ were obtained indirectly, since gas expansion measurements at these low densities were not possible. Pressures were obtained using an air deadweight gage while the density was obtained by heating the PVT cell to $175 \mathrm{~K}$ using an extrapolation of the previously determined pressure-density relationship for that isotherm obtained from higher density measurements. 
TABLE 1. TEMPERATURE-FRESSURE-DENSITY OBSERVATIONS ON FLUORINE

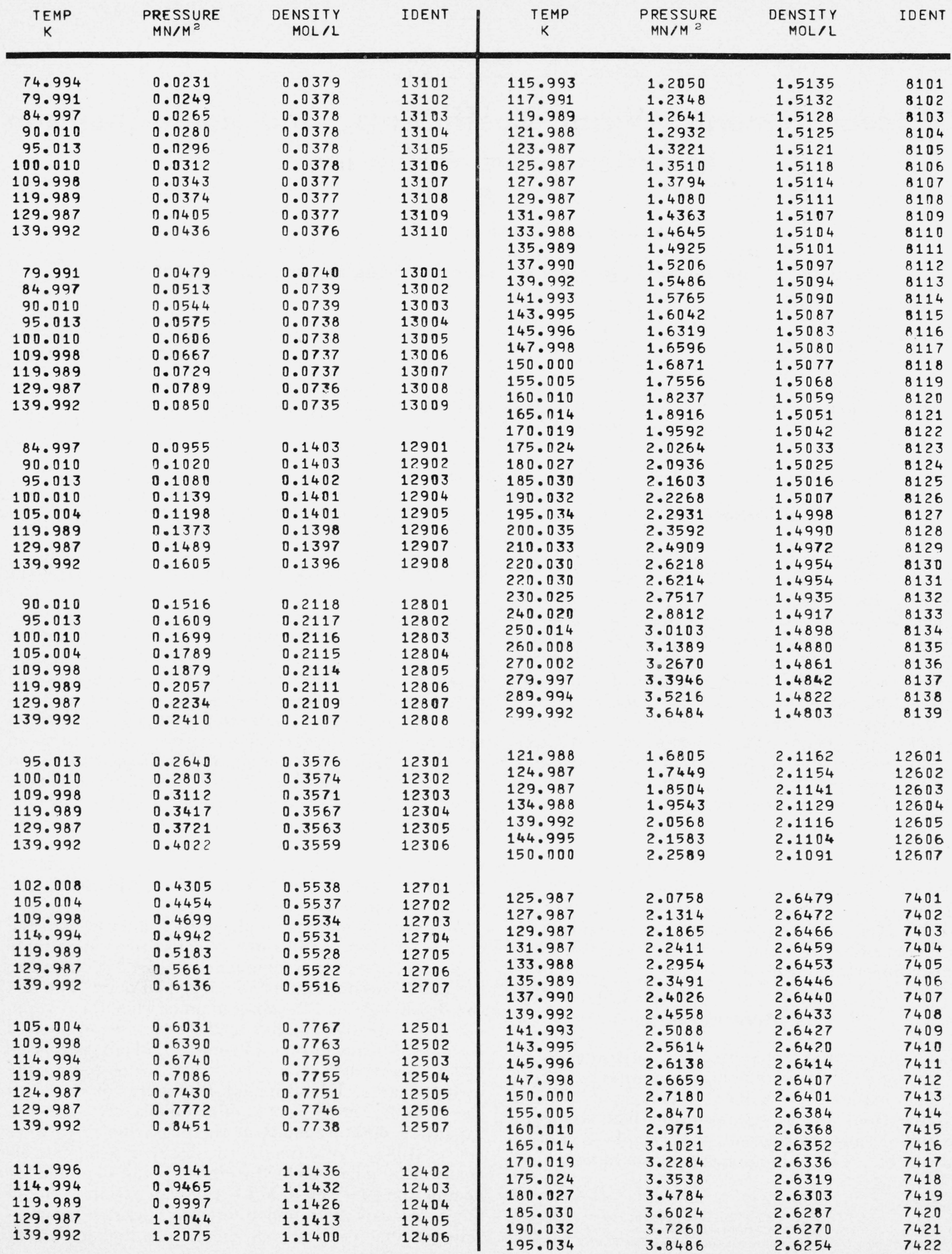




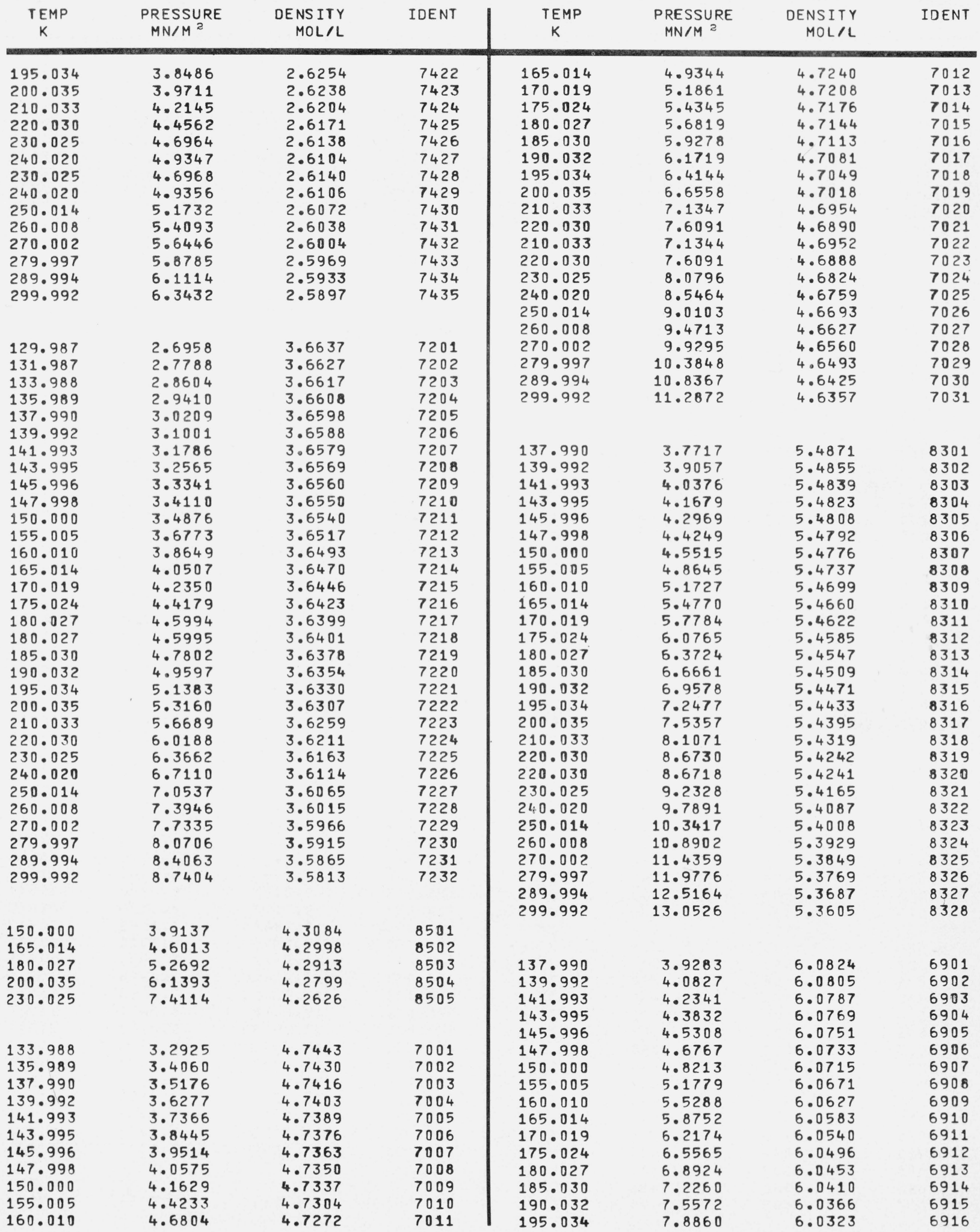


TABLE 1 . TEMPERATURE_FRESSURE_DENSITY OBSERVATIONS ON FLUORINE_-CONTINUED

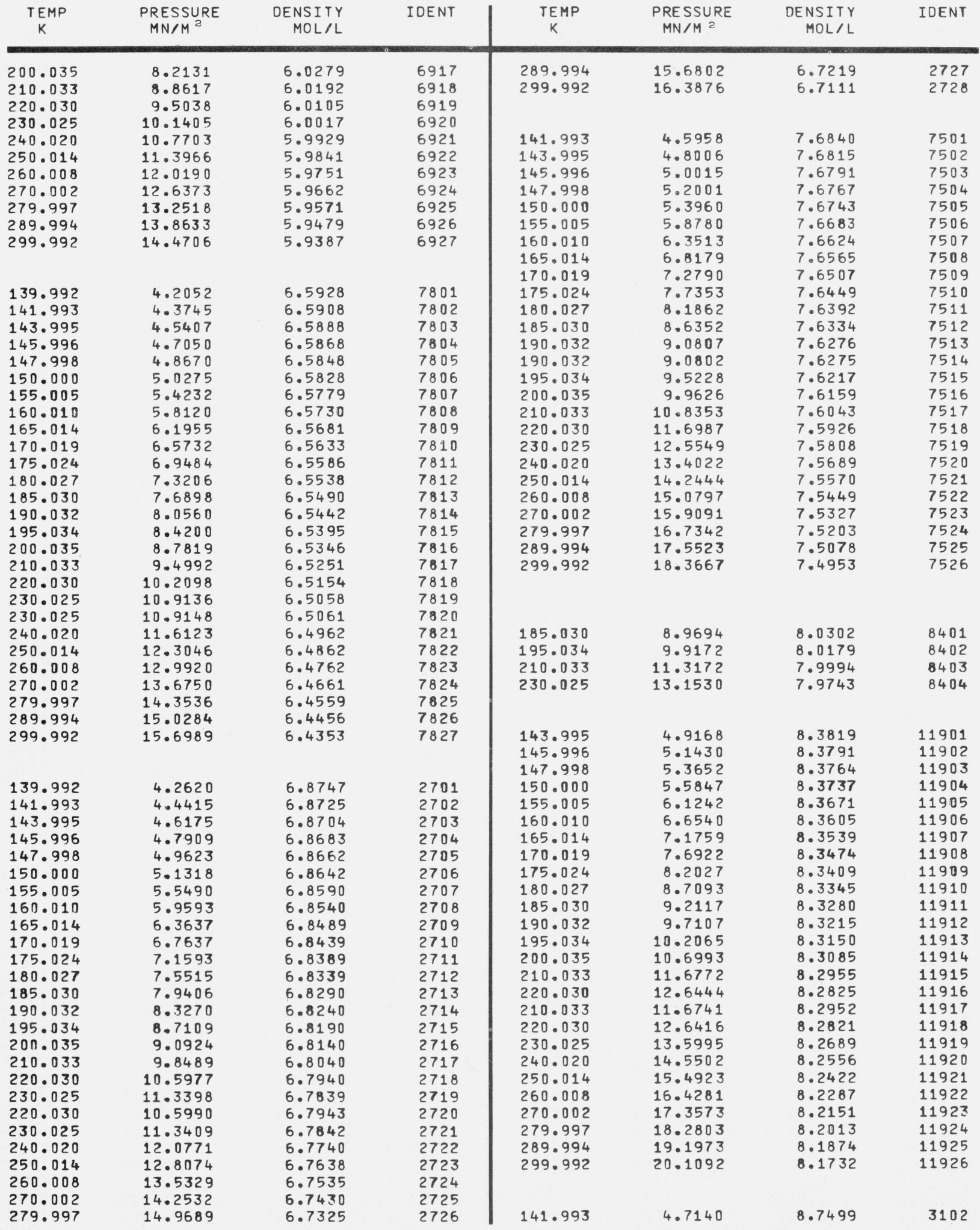




\begin{tabular}{|c|c|c|c|c|c|c|c|}
\hline $\begin{array}{l}\text { TEMP } \\
K\end{array}$ & $\begin{array}{l}\text { PRESSURE } \\
M N / M^{2}\end{array}$ & $\begin{array}{c}\text { DENSITY } \\
\text { MOL } / L\end{array}$ & IDENT & $\begin{array}{l}\text { TEMP } \\
\mathrm{K}\end{array}$ & $\begin{array}{l}\text { PRESSURE } \\
M N / M\end{array}$ & $\begin{array}{c}\text { DENSITY } \\
\text { MOL } / L\end{array}$ & IDENT \\
\hline 143.995 & 4.9677 & 8.7468 & 3103 & 200.035 & 12.1356 & 9.6809 & 7614 \\
\hline 145.996 & 5.2069 & 8.7439 & 3104 & 210.033 & 13.3343 & 9.6649 & 7615 \\
\hline 147.998 & 5.4421 & 8.7411 & 3105 & 220.030 & 14.5208 & 9.6488 & 7616 \\
\hline 150.000 & 5.6739 & 8.7382 & 3106 & 230.025 & 15.6937 & 9.6326 & 7617 \\
\hline 155.005 & 6.2440 & 8.7312 & 3107 & 230.025 & 15.6950 & 9.6329 & 7618 \\
\hline 160.010 & 6.8033 & 8.7243 & 3108 & 240.020 & 16.8613 & 9.6166 & 7619 \\
\hline 165.014 & 7.3548 & 8.7174 & 3109 & 250.014 & 18.0166 & 9.6000 & 7620 \\
\hline 170.019 & 7.9002 & 8.7105 & 3110 & 260.008 & 19.1645 & 9.5833 & 7621 \\
\hline 175.024 & 8.4399 & 8.7037 & 3111 & 270.002 & 20.3049 & 9.5663 & 7622 \\
\hline 180.027 & 6.9755 & 8.6969 & 3112 & & & & \\
\hline 185.030 & 9.5067 & 8.6901 & 3113 & & & & \\
\hline 190.032 & 10.0342 & 8.6833 & 3114 & 143.995 & 5.1231 & 10.8686 & 8001 \\
\hline 195.034 & 10.5584 & 8.6765 & 3115 & 145.996 & 5.4415 & 10.8647 & 8002 \\
\hline 200.035 & 11.0798 & 8.6697 & 3116 & 147.998 & 5.7518 & 10.8608 & 8003 \\
\hline 210.033 & 12.1133 & 8.6560 & 3117 & 150.000 & 6.0578 & 10.8570 & 8004 \\
\hline 220.030 & 13.1363 & 8.6423 & 3118 & 155.005 & 6.8106 & 10.8477 & 8005 \\
\hline 220.030 & 13.1341 & 8.6416 & 3119 & 160.010 & 7.5519 & 10.8384 & 8006 \\
\hline 230.025 & 14.1478 & 8.6278 & 3120 & 165.014 & 8.2847 & 10.8291 & 8007 \\
\hline 240.020 & 15.1530 & 8.6140 & 3121 & 170.019 & 9.0106 & 10.8199 & 8008 \\
\hline 250.014 & 16.1502 & 8.6000 & 3122 & 175.024 & 9.7306 & 10.8108 & 8009 \\
\hline 260.008 & 17.1403 & 8.5859 & 3123 & 180.027 & 10.4459 & 10.8016 & 8010 \\
\hline 270.002 & 18.1231 & 8.5717 & 3124 & 185.030 & 11.1567 & 10.7925 & 8011 \\
\hline 279.997 & 19.0990 & 8.5572 & 3125 & 190.032 & 11.8630 & 10.7834 & 8012 \\
\hline 289.994 & 20.0680 & 8.5426 & 3126 & 195.034 & 12.5659 & 10.7742 & 8013 \\
\hline \multirow[t]{3}{*}{299.992} & 21.0320 & 8.5278 & 3127 & 200.035 & 13.2650 & 10.7650 & 8014 \\
\hline & & & & 210.033 & 14.6522 & 10.7466 & 8015 \\
\hline & & & & 220.030 & 16.0262 & 10.7279 & 8016 \\
\hline 143.995 & 4.9995 & 9.0187 & 8201 & 230.025 & 17.3881 & 10.7092 & 8017 \\
\hline 145.996 & 5.2489 & 9.0157 & 8202 & 240.020 & 18.7385 & 10.6903 & 8018 \\
\hline 147.998 & 5.4935 & 9.0127 & 8203 & 250.014 & 20.0784 & 10.6712 & 8019 \\
\hline 150.000 & 5.7349 & 9.0097 & 8204 & 260.008 & 21.4083 & 10.6519 & 8020 \\
\hline 155.005 & 6.3276 & 9.0024 & 8205 & & & & \\
\hline 160.010 & 6.9099 & 8.9953 & 8206 & & & & \\
\hline 165.014 & 7.4838 & 8.9881 & 8207 & 145.996 & 5.5018 & 11.9244 & 7902 \\
\hline 170.019 & 8.0512 & 8.9809 & 8208 & 147.998 & 5.8491 & 11.9201 & 7903 \\
\hline 175.024 & 8.6132 & 8.9738 & 8209 & 150.000 & 6.1922 & 11.9159 & 7904 \\
\hline 180.027 & 9.1705 & 8.9667 & 8210 & 155.005 & 7.0392 & 11.9053 & 7905 \\
\hline 185.030 & 9.7235 & 8.9596 & 8211 & 160.010 & 7.8758 & 11.8948 & 7906 \\
\hline 190.032 & 10.2729 & 8.9524 & 8212 & 165.014 & 8.7053 & 11.8843 & 7907 \\
\hline 195.034 & 10.8190 & 8.9453 & 8213 & 170.019 & 9.5289 & 11.8739 & 7908 \\
\hline 200.035 & 11.3619 & 8.9381 & 8214 & 175.024 & 10.3471 & 11.8634 & 7909 \\
\hline 143.995 & 4. 9977 & 9.0186 & 8215 & 180.027 & 11.1599 & 11.8530 & 7910 \\
\hline 170.019 & 8.0504 & 8.9805 & 8216 & 185.030 & 11.9686 & 11.8425 & 7911 \\
\hline 200.035 & 11.3610 & 8.9378 & 8217 & 190.032 & 12.7733 & 11.8321 & 7912 \\
\hline 210.033 & 12.4354 & 8.9234 & 8218 & 195.034 & 13.5742 & 11.8216 & 7913 \\
\hline 220.030 & 13.5009 & 8.9090 & 8219 & 200.035 & 14.3705 & 11.8111 & 7914 \\
\hline 230.025 & 14.5573 & 8.8945 & 8220 & 210.033 & 15.9527 & 11.7900 & 7915 \\
\hline 240.020 & 15.6029 & 8.8798 & 8221 & 220.030 & 17.5202 & 11.7687 & 7916 \\
\hline 250.014 & 16.6415 & 8.8650 & 8222 & 230.025 & 19.0742 & 11.7472 & 7917 \\
\hline 260.008 & 17.6717 & 8.8501 & 8223 & 240.020 & 20.6152 & 11.7254 & 7918 \\
\hline 270.002 & 18.6956 & 8.8349 & 8224 & & & & \\
\hline 279.997 & 19.7114 & 8.8197 & 8225 & & & & \\
\hline \multirow[t]{3}{*}{289.994} & 20.7215 & 8.8043 & 8226 & 145.996 & 5.5529 & 13.4190 & 7701 \\
\hline & & & & 147.998 & 5.9507 & 13.4141 & 7702 \\
\hline & & & & 150.000 & 6.3460 & 13.4092 & 7703 \\
\hline 143.995 & 5.0676 & 9.7709 & 7601 & 155.005 & 7.3299 & 13.3969 & 7704 \\
\hline 145.996 & 5.3447 & 9.7675 & 7602 & 160.010 & 8.3087 & 13.3846 & 7705 \\
\hline 147.998 & 5.6161 & 9.7641 & 7603 & 165.014 & 9.2833 & 13.3724 & 7706 \\
\hline 150.000 & 5.8835 & 9.7608 & 7604 & 170.019 & $10 \cdot 2538$ & 13.3601 & 7707 \\
\hline 155.005 & 6.5404 & 9.7527 & 7605 & 175.024 & 11.2199 & 13.3478 & 7708 \\
\hline 160.010 & 7.1858 & 9.7446 & 7606 & 180.027 & 12.1821 & 13.3355 & 7709 \\
\hline 165.014 & 7.8231 & 9.7366 & 7607 & 185.030 & 13.1408 & 13.3232 & 7710 \\
\hline 170.019 & 8.4535 & 9.7286 & 7608 & 190.032 & 14.0952 & 13.3108 & 7711 \\
\hline 175.024 & 9.0778 & 9.7206 & 7609 & 195.034 & 15.0452 & 13.2983 & 7712 \\
\hline 180.027 & 9.6972 & 9.7127 & 7610 & 200.035 & 15.9911 & 13.2858 & 7713 \\
\hline 185.030 & 10.3125 & 9.7047 & 7611 & 210.033 & 17.8715 & 13.2606 & 7714 \\
\hline 190.032 & 10.9239 & 9.6968 & 7612 & 220.030 & 19.7353 & 13.2351 & 7715 \\
\hline 195.034 & 11.5312 & 9.6888 & 7613 & 230.025 & 21.5840 & 13.2092 & 7716 \\
\hline
\end{tabular}




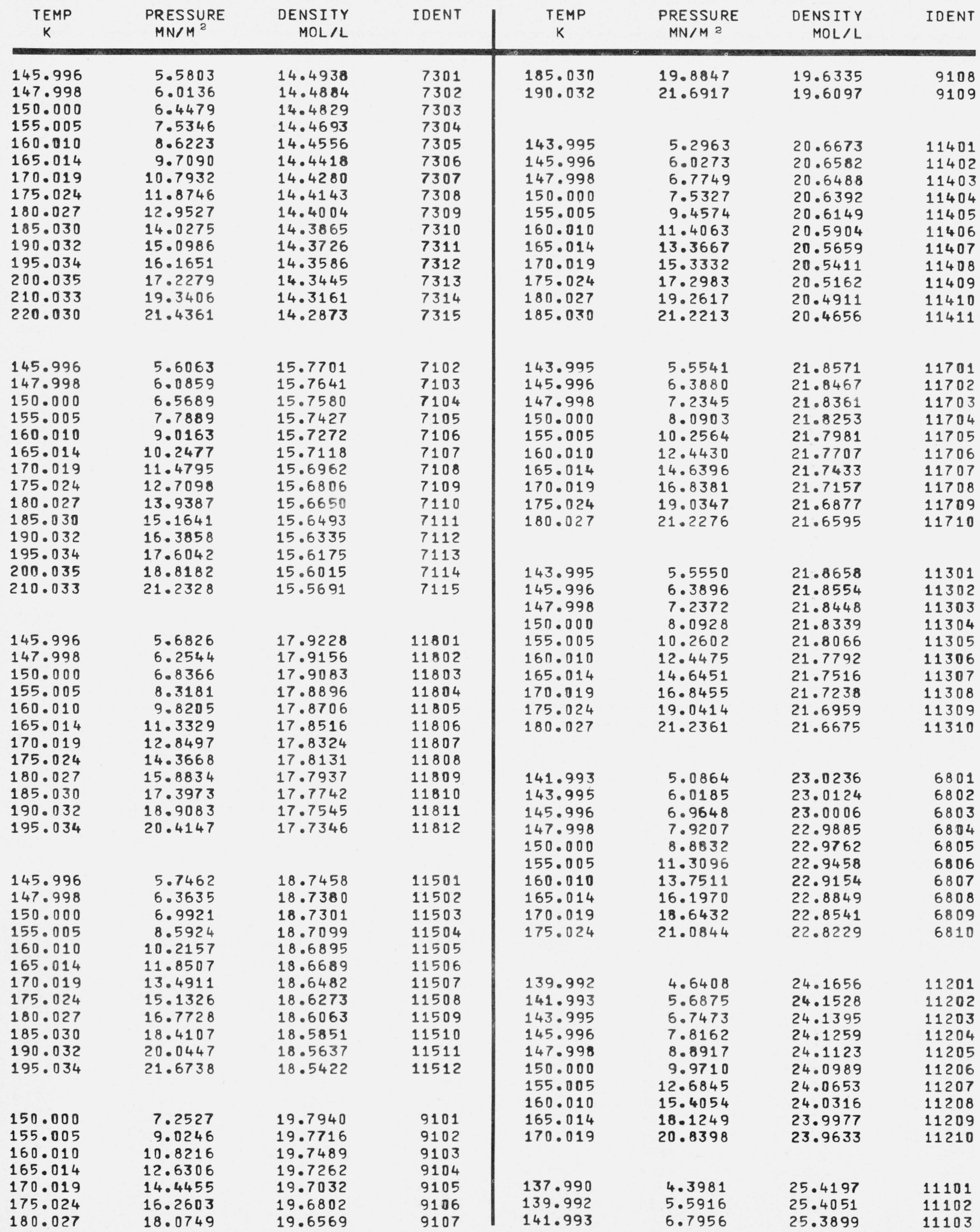




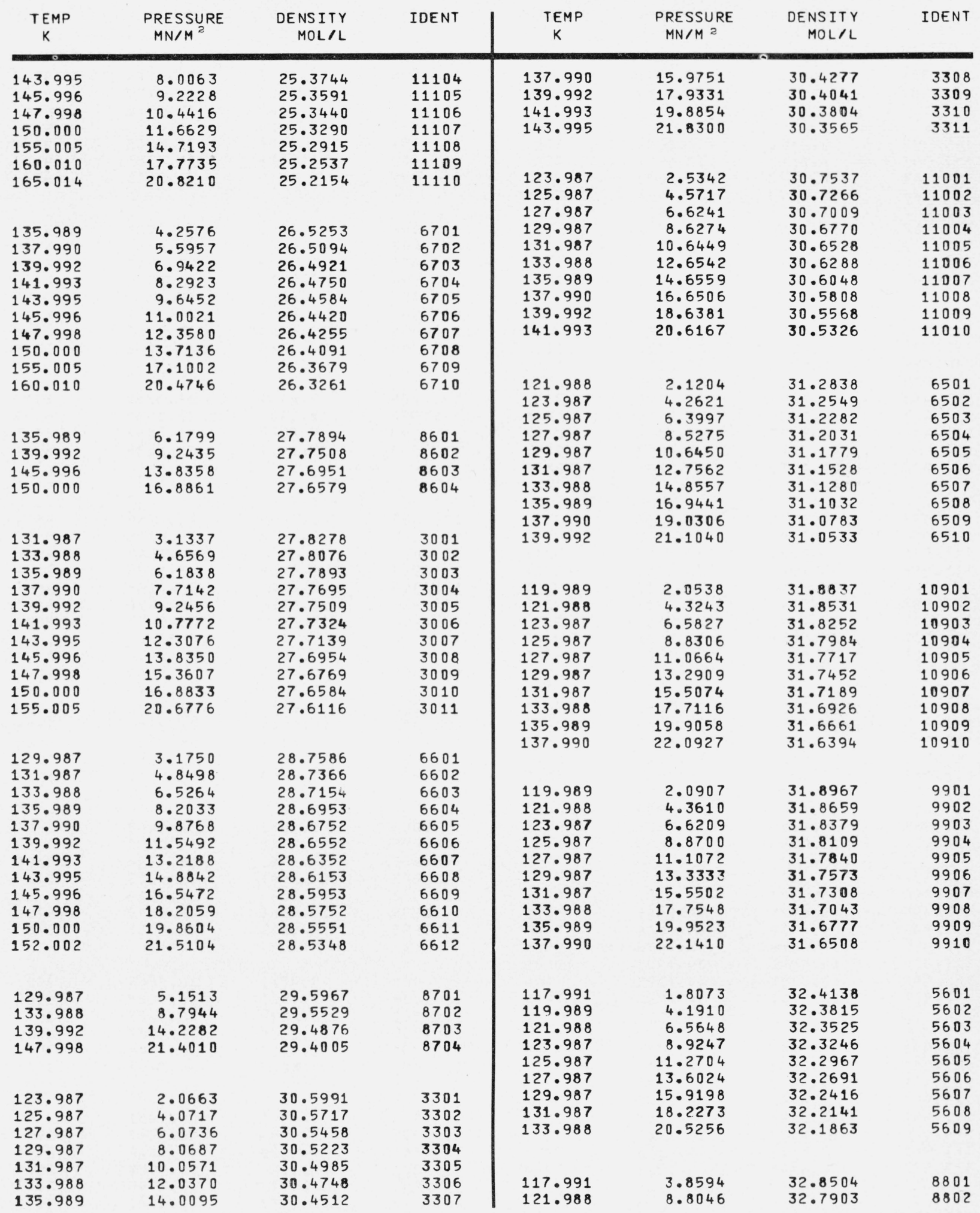


TABLE 1. TEMPERATURE-PRESSURE-DENSITY OBSERVATIONS ON FLUORINE_-CONTINUED

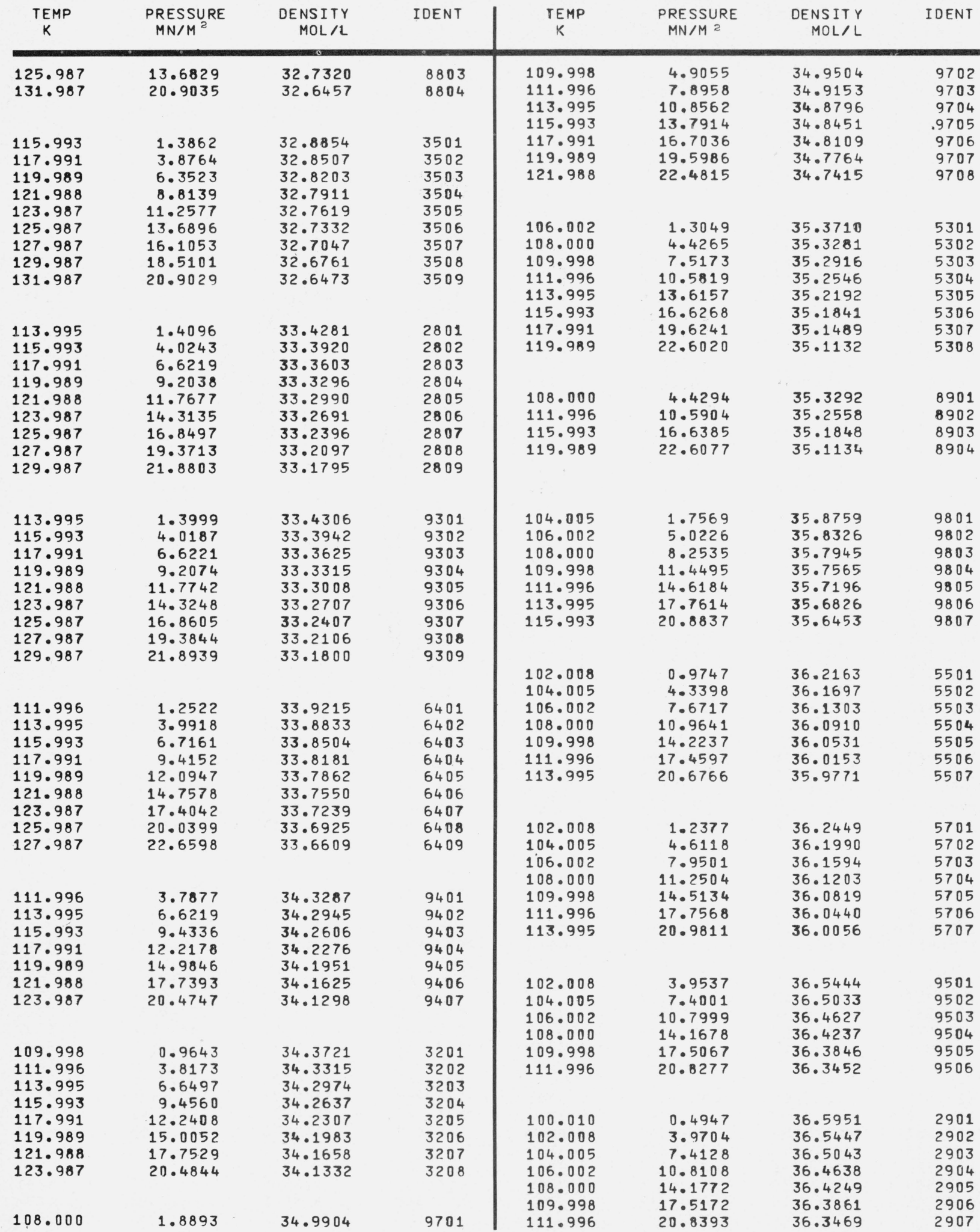


TABLE 1. TEMPERATURE_PRESSURE_-DENSITY OBSERVATIONS ON FLUORINE - - CONTINUED

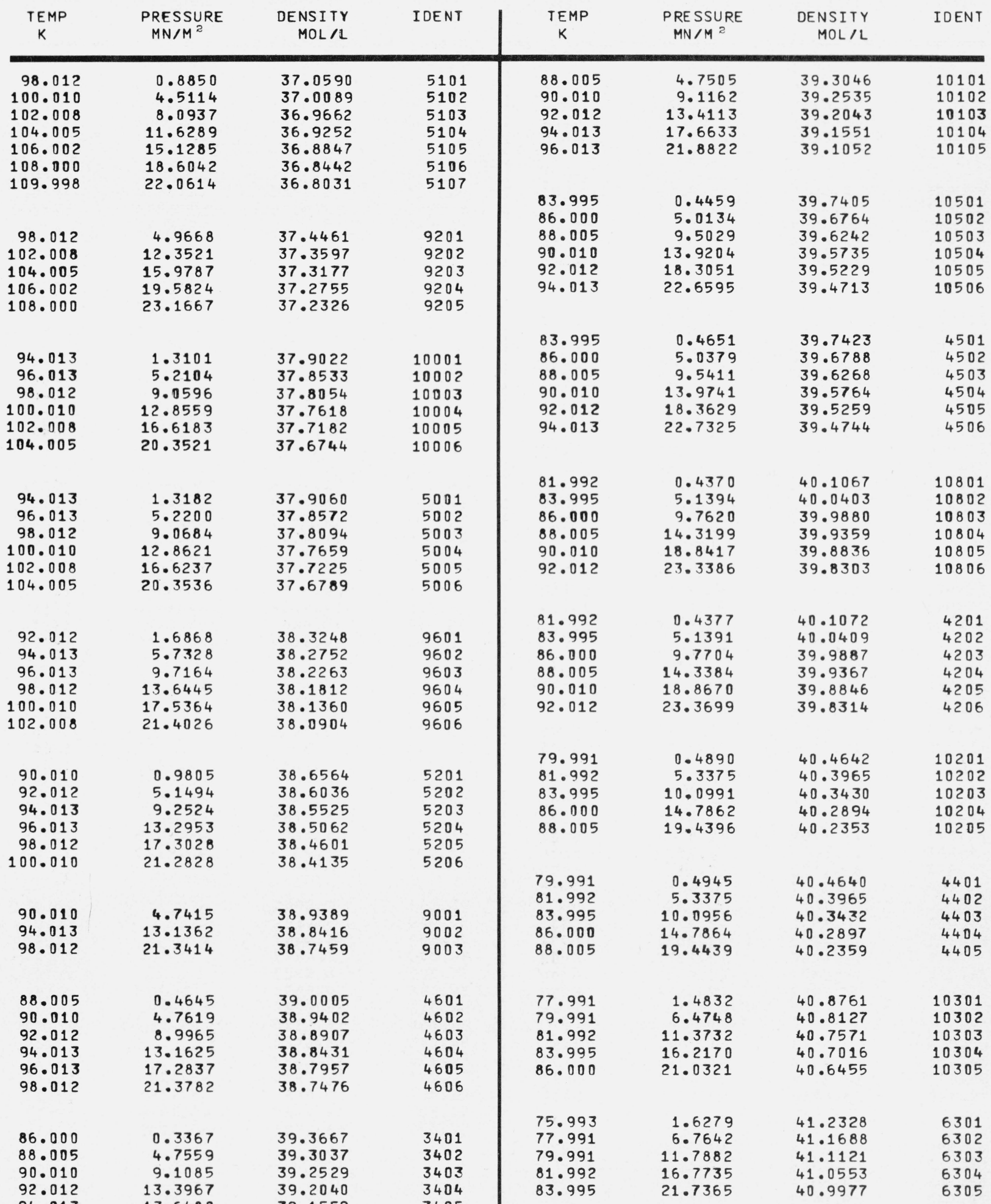


TABLE 1. TEMFERA TURE-PRESSURE-DENSITY OBSERVATIONS ON FLUORINE--CONTINUED

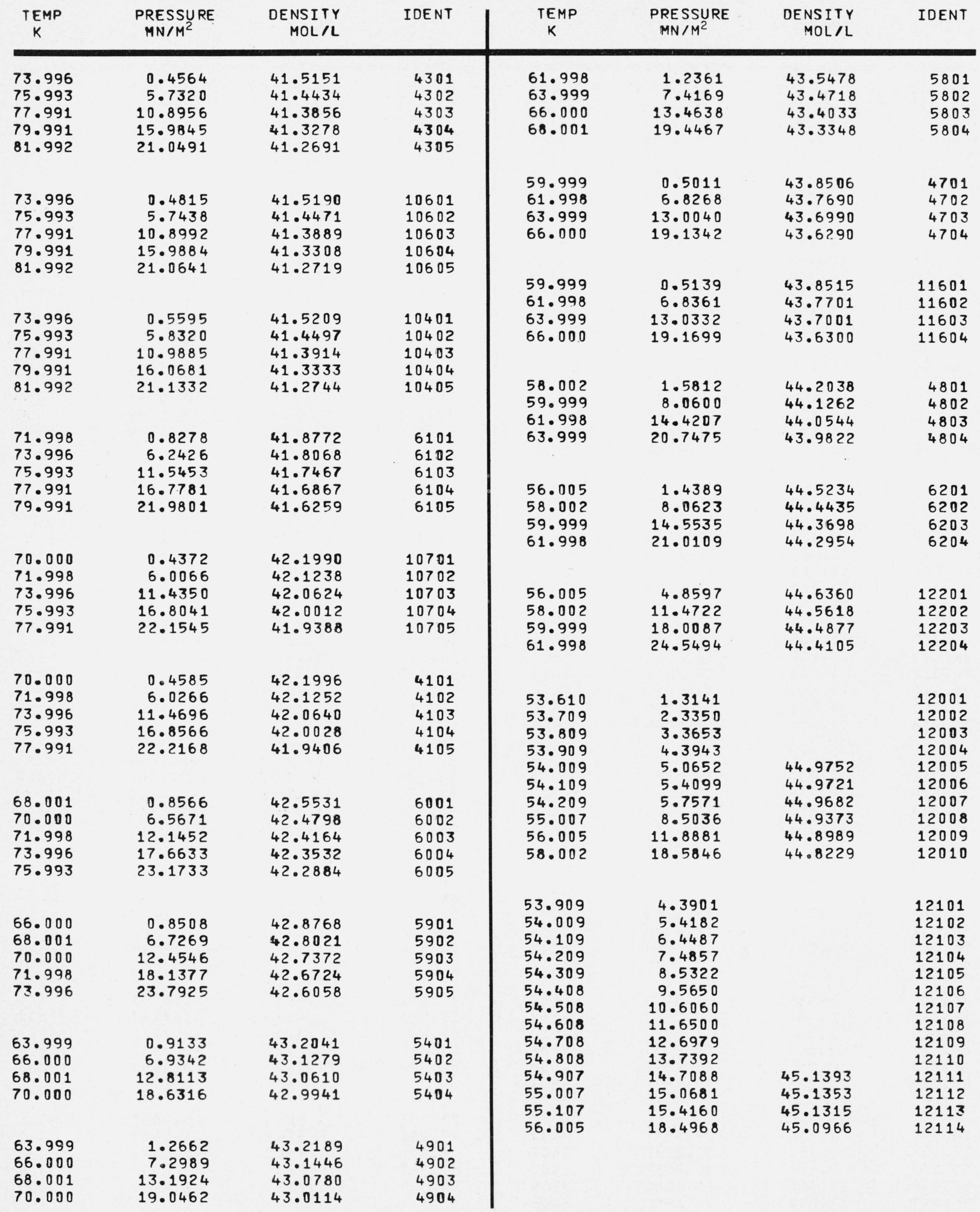


The estimated accuracy of the density measurements is 0.1 percent. However, the corresponding precision is better, indicated by the fact that the standard deviation of all PVT data from eqs (1) and (5) is approximately 0.02 percent in density.

The purity of the fluorine sample used for these measurements was 99.99 percent as determined from residual gas analysis after reaction of fluorine with mercury.

\section{Representation of PVT Data}

No single equation of state was found capable of representing the data to within its precision. Therefore, to obtain the best possible representation of all the data for computation of thermodynamic functions, the PVT surface was divided into two regions as pictured in figure 1. The data in each region were correlated separately as discussed below.

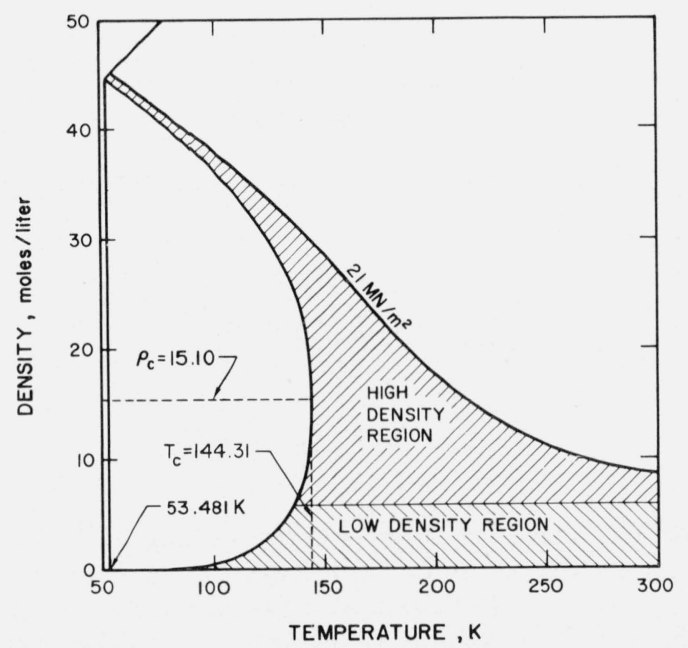

FIGURE 1. Density-temperature diagram showing the regions used for representation of the PVT data.

\subsection{Low-Density Region}

All experimental $P V T$ data at densities less than 6.0 $\mathrm{mol} / \mathrm{l}$ were represented by the truncated virial equation

$$
P=R T\left[\rho+B(T) \rho^{2}+C(T) \rho^{3}\right]
$$

where $R=8.3143 \mathrm{~J} / \mathrm{mol}-\mathrm{K}$. The decision to use 6.0 $\mathrm{mol} / \mathrm{l}$ as a maximum density value for the virial surface was based on the results obtained by fitting the experimental data to eq (1). By varying the maximum experimental density included in the fit of the virial equation, the data were found to exhibit definite systematic deviations in density as well as temperature for all densities greater than $6.0 \mathrm{~mol} / \mathrm{l}$. Equation (1) was based on $329 P V T$ data points in the virial region. Further, 26 measured specific heat $\left(C_{v}\right)$ data points [9] between 6.5 and $6.8 \mathrm{~mol} / \mathrm{l}$ at temperatures from $140 \mathrm{~K}$ to $300 \mathrm{~K}$ were compared to $C_{v}$ values calculated from the virial equation and the ideal gas values, $C_{v}^{\circ}[8]$. The reason for this was to ascertain that the apparent deviations, being of the order of 1.5 percent, were fairly constant and not a function of temperature.

The second and third virial coefficients were represented by

$$
B(T)=\sum_{i=1}^{5} B_{i} T^{(1-i) / 4}
$$

and

$$
C(T)=\sum_{i=1}^{6} C_{i} T^{(1-i) / 2}
$$

respectively. An iterative method was used to optimize both the number of coefficients of $B(T)$ and $C(T)$ and their temperature dependence. The coefficients of eqs (la) and (1b) and their significance level obtained through a weighted least-squares fit of all $P V T$ data in this region are given in table 2 . Weight factors, $W$, used in the fitting of eq (1) were defined as

TABLE 2. Least squares estimate of the coefficients of eqs (la) and ( $1 b)$

\begin{tabular}{c|c|l|c}
\hline \hline Coefficient & $\begin{array}{c}\text { Least squares } \\
\text { estimate of } \\
\text { coefficient }\end{array}$ & $\begin{array}{c}\text { Standard } \\
\text { deviation } \\
\text { of coefficient }\end{array}$ & $\begin{array}{c}\text { Significance } \\
\text { level in } \\
\text { percent }\end{array}$ \\
\hline$B_{1}$ & -4.43719523 & 1.10 & $99.9+$ \\
$B_{2}$ & $6.88646977 \times 10$ & $1.61 \times 10$ & $99.9+$ \\
$B_{3}$ & $-4.00652537 \times 10^{2}$ & $8.85 \times 10$ & $99.9+$ \\
$B_{4}$ & $1.04730534 \times 10^{3}$ & $2.15 \times 10^{2}$ & $99.9+$ \\
$B_{5}$ & $-1.05492603 \times 10^{3}$ & $1.96 \times 10^{2}$ & $99.9+$ \\
$C_{1}$ & $3.97288149 \times 10^{-1}$ & $6.38 \times 10^{-2}$ & $99.9+$ \\
$C_{2}$ & $-2.80769183 \times 10^{2}$ & 4.33 & $99.9+$ \\
$C_{3}$ & $7.95698766 \times 10^{2}$ & $1.18 \times 10^{2}$ & $99.9+$ \\
$C_{4}$ & $-1.12867697 \times 10^{4}$ & $1.59 \times 10^{3}$ & $99.9+$ \\
$C_{5}$ & $8.01450388 \times 10^{4}$ & $1.08 \times 10^{4}$ & $99.9+$ \\
$C_{6}$ & $-2.27594177 \times 10^{5}$ & $2.93 \times 10^{4}$ & $99.9+$ \\
\hline
\end{tabular}

a These parameters are significant at the level indicated when applying the standard $F$-test.

$$
W=\frac{1}{\sigma_{p}^{2}+\left(\frac{\partial P}{\partial \rho} \sigma_{\rho}\right)^{2}+\left(\frac{\partial P}{\partial T} \sigma_{T}\right)^{2}}
$$

where $\sigma_{p}^{2}, \sigma_{\rho}^{2}, \sigma_{T}^{2}$ are the respective variances in pressure, density, and temperature. PVT data below $100 \mathrm{~K}$ were weighted relatively less than above this temperature, as the uncertainty of the measurements in this region increases rapidly with decreasing density. The weighted standard deviation in density between the virial surface and all of the $329 P V T$ data points is 0.041 percent. For consistency eq (1) was constrained to give the proper saturation temperature $(137.327 \mathrm{~K})$ for the $6.0 \mathrm{~mol} / \mathrm{l}$ isochore $[2]$.

The second and third virial coefficients, calculated from eqs (1a) and (1b), are given in table 3. Also given in this table are the quantities $\delta B$ and $\delta C$, which are the respective estimated uncertainties of the coefficients based on experience gained when fitting the virial surface. A comparison of the second virial coefficient with values obtained by White, Hu, and 
TABLE 3. Second and third virial coefficients of fluorine

( $\delta B$ and $\delta C$ are estimated uncertainties)

\begin{tabular}{|c|c|c|c|c|}
\hline$T$ & $B$ & $\delta B \times 10^{3}$ & C & $\delta C \times 10^{3}$ \\
\hline $\begin{array}{l}K \\
80\end{array}$ & $\begin{array}{c}l / \mathrm{mol} \\
-0.2396\end{array}$ & $\begin{array}{r}\text { l/mol } \\
40\end{array}$ & $\begin{array}{c}l / m o l^{2} \\
-0.022557\end{array}$ & $\begin{array}{c}(1 / m o l)^{2} \\
20\end{array}$ \\
\hline 85 & -.2132 & & -.013548 & \\
\hline 90 & -.1910 & & -.007748 & \\
\hline 95 & -.1722 & & -.004016 & \\
\hline 100 & -.1561 & 10 & -.001624 & 3 \\
\hline 105 & -.1422 & & -.000106 & \\
\hline 110 & -.1301 & & .000838 & \\
\hline 115 & -.1194 & & .001409 & \\
\hline 120 & -.1100 & & .001736 & \\
\hline 125 & -.1017 & 2 & .001905 & 0.5 \\
\hline 130 & -.0942 & & .001973 & \\
\hline 135 & -.0875 & & .001979 & \\
\hline 140 & -.0815 & & .001947 & \\
\hline 145 & -.0759 & & .001893 & \\
\hline 150 & -.0709 & 0.3 & .001828 & .03 \\
\hline 155 & -.0663 & & .001758 & \\
\hline 160 & -.0621 & & .001689 & \\
\hline 165 & -.0582 & & .001621 & \\
\hline 170 & -.0546 & & .001557 & \\
\hline 175 & -.0512 & & .001498 & \\
\hline 180 & -.0481 & & .001442 & \\
\hline 185 & -.0452 & & .001391 & \\
\hline 190 & -.0425 & & .001344 & \\
\hline 195 & -.0400 & & .001301 & \\
\hline 200 & -.0376 & .3 & .001261 & .03 \\
\hline 205 & -.0354 & & .001224 & \\
\hline 210 & -.0332 & & .001190 & \\
\hline 215 & -.0313 & & .001159 & \\
\hline 220 & -.0294 & & .001130 & \\
\hline 225 & -.0276 & & .001104 & \\
\hline 230 & -.0259 & & .001080 & \\
\hline 235 & -.0243 & & .001057 & \\
\hline 240 & -.0228 & & .001037 & \\
\hline 245 & -.0214 & & .001019 & \\
\hline 250 & -.0200 & .3 & .001003 & .03 \\
\hline 255 & -.0187 & & .000988 & \\
\hline 260 & -.0175 & & .000976 & \\
\hline 265 & -.0163 & & .000966 & \\
\hline 270 & -.0152 & & .000957 & \\
\hline 275 & -.0141 & & .000951 & \\
\hline 280 & -.0131 & & .000947 & \\
\hline 285 & -.0122 & & .000946 & \\
\hline 290 & -.0112 & & .000946 & \\
\hline 295 & -.0104 & & .000949 & \\
\hline 300 & -.0095 & .3 & .000955 & .04 \\
\hline
\end{tabular}

Johnston [10] is given in figure 2. In the calculation of their data these authors neglected the contribution of the third and higher order virial coefficients, which is the probable reason for their larger negative values, especially at lower temperatures. Temperature scale differences could also account for part of the deviations. Since the data from reference [10] do not represent just the second virial coefficient, further comparisons with eq (la) were made by converting values from oxygen [11] and argon [12] using corresponding states approach based on critical parameters

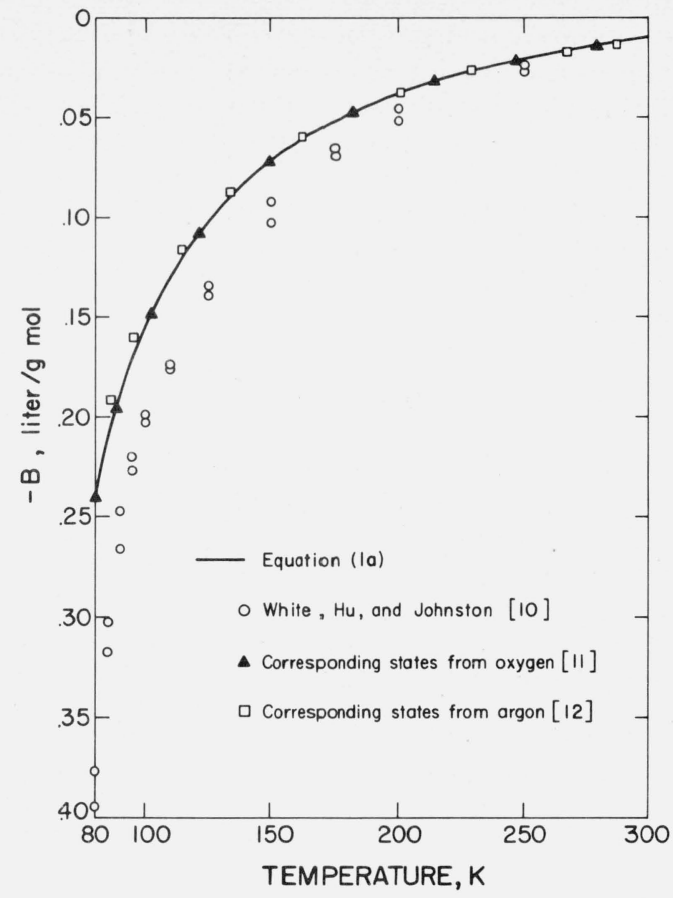

Figure 2. Comparisons of second virial coefficients of fluorine. as follows:

and

$$
B_{\text {converted }}=B(X) \frac{\rho_{c}(X)}{\rho_{c}\left(F_{2}\right)}
$$

$$
T_{\text {converted }}=T(X) \frac{T_{c}\left(F_{2}\right)}{T_{c}(X)}
$$

where $X$ represents either oxygen or argon. The agreement is good as may be seen from figure 2 . In fact, the correspondence between values calculated from the second virial coefficient of oxygen and eq (la) is better than one may justifiably expect from the principle of corresponding states.

\subsection{High-Density Region}

a. Isotherm Representation

The isotherms in the high-density region (see fig. 1) were represented by polynomials of the form

$$
P=R T \rho+\sum_{i=1}^{n} A_{i} \rho^{i-1}
$$

where $A_{1}=A_{2}=0$ for $T>T_{c}$ or $\rho<\rho_{c}$. No more than 3 coefficients were used for the isotherms below $60 \mathrm{~K}$ since these consisted of only $4 P-\rho$ data points each. As many as 9 coefficients were necessary for the $146 \mathrm{~K}$ and $148 \mathrm{~K}$ isotherms (slightly above the critical temperature) to adequately represent the data. From 4 to 7 coefficients were needed to represent all of the remaining isotherms. The isotherms in the compressed liquid and vapor phases below the critical temperature were constrained to the corresponding saturation 
density from reference [2] (see also Appendix). Above $138 \mathrm{~K}$ the isotherms were also fitted to the low density data in the virial region to provide a better match of the surfaces around the $6.0 \mathrm{~mol} / \mathrm{l}$ isochore.

The standard deviation of the 381 experimental data points in the compressed liquid was only 0.005 percent while the 540 compressed vapor data points exhibit a larger deviation of 0.018 percent. The latter value is higher due mainly to the contribution from the isotherms just above the critical temperature where the deviations are much larger than over the rest of the surface.

\section{b. Isochore Representation}

Many calculations of thermodynamic properties require knowledge of the derivatives $(\partial P / \partial T)_{\rho}$ and $\left(\partial^{2} P / \partial T^{2}\right)_{\rho}$. In the low-density region these derivatives may be calculated directly from eq (1). For densities above $6.0 \mathrm{~mol} / \mathrm{l}$ it was first necessary to derive true isochores by calculating pressures at even density increments using the isotherm representations. Density increments of $0.5 \mathrm{~mol} / \mathrm{l}$ were used for the 80 isochores between 5.5 and $45.0 \mathrm{~mol} / \mathrm{l}$. The true isochores were then represented using functions of the form

$$
P=\sum_{i=1}^{n} A_{i} T^{(3-2 i)}
$$

The number of terms ${ }^{2}$ of eq (6) varied from 7 at the lowest density to 3 at the $45.0 \mathrm{~mol} / \mathrm{l}$ isochore. The good fit of the isotherms was directly carried over in the correlation of these isochores.

\section{Derived Properties}

\subsection{Densities of the Liquid at Freezing}

Density calculations of the PVT surface below $56 \mathrm{~K}$ were obtained by extrapolating isobars computed from the isotherms between $56 \mathrm{~K}$ and $64 \mathrm{~K}$. The density of the liquid in equilibrium with the solid derived from the intersections of these isobars with the melting curve, reference [3], was expressed as a function of either temperature or pressure by

or

$$
\rho_{\text {melt } L}=\rho_{t}+0.208\left(T-T_{t}\right), \mathrm{mol} / \mathrm{l}
$$

$$
\rho_{\text {melt } L}=\rho_{t}+0.020 P\left(\mathrm{MN} / \mathrm{m}^{2}\right) .
$$

A value of $44.86_{2} \mathrm{~mol} / \mathrm{l}$ was used for the liquid density, $\rho_{t}$, at the triple point.

\subsection{The Joule-Thomson Inversion Curve}

Calculated points on the Joule-Thomson inversion curve are given in table 4 . This curve is defined as the locus of points where the Joule-Thomson coefficient is equal to zero. This condition may be described in classical thermodynamics by the relationship ${ }^{2}$ The coefficients of the 70 isotherms and the 80 isochores discussed above, may be
obtained from the Cryogenic Data Center, National Bureau of Standards, Boulder, Colorado 80302 .

$$
\frac{-T}{\rho^{2}}\left(\frac{\partial \rho}{\partial T}\right)_{p}=\frac{1}{\rho}
$$

or more conveniently

$$
T\left(\frac{\partial P}{\partial T}\right)_{\rho}=\rho\left(\frac{\partial P}{\partial \rho}\right)_{T}
$$

Equation (10) was solved by an iterative technique using the isotherm derivatives, $(\partial P / \partial \rho)_{T}$, and the isochore derivatives, $(\partial P / \partial T)_{\rho}$, obtained from eqs (5) and (6), respectively. The computed pressure errors in table 4 are based on an assumed uncertainty of 1 percent in these derivatives. No published Joule-Thomson data for fluorine are available for comparison to values tabulated in table 4. However, a comparison with oxygen [11] and argon [12] using the theory of corresponding states based on critical parameters, is given in figure 3 .

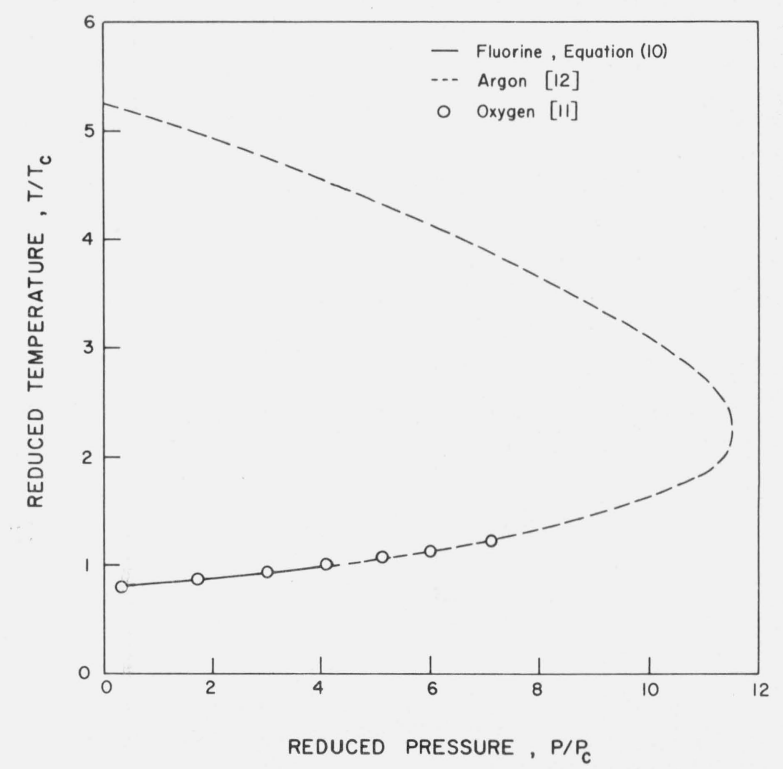

FIGURE 3. Comparisons of reduced Joule-Thomson inversion curves of fluorine, oxygen, and argon.

TABLE 4. The Joule-Thomson inversion curve

\begin{tabular}{cccc}
\hline \hline$T$ & $P$ & Density & $\Delta P a$ \\
\hline$K$ & $M N / m^{2}$ & Molll & $M N / m^{2}$ \\
118 & 2.732 & 32.615 & 0.19 \\
120 & 4.340 & 32.411 & 0.21 \\
122 & 6.092 & 32.250 & 0.22 \\
124 & 7.649 & 32.058 & 0.23 \\
126 & 9.288 & 31.895 & 0.23 \\
& & & \\
128 & 10.861 & 31.727 & 0.25 \\
130 & 12.373 & 31.556 & 0.25 \\
132 & 13.824 & 31.381 & 0.26 \\
134 & 15.278 & 31.214 & 0.26 \\
136 & 16.583 & 31.024 & 0.28 \\
& & & \\
138 & 17.980 & 30.864 & 0.27 \\
140 & 19.155 & 30.664 & 0.26 \\
142 & 20.811 & 30.573 & 0.31 \\
144 & 21.668 & 30.322 & 0.31 \\
\hline
\end{tabular}

${ }^{a}$ These estimated pressure errors are due to a 1 percent assumed uncertainty in either the isotherm or the isochore derivative. 
The authors acknowledge the support of the Air Force Rocket Propulsion Laboratory, Edwards, California. Also, thanks are due to G. K. Johnson of Argonne National Laboratory for supplying the purified fluorine used in these experiments.

\section{Appendix}

Given below are correlations for different properties of fluorine as reported earlier. The number of significant figures given for the coefficients is not justified on the basis of the uncertainty of the data, but are presented to enable duplication of the calculated values.

\section{Vapor Pressure}

The following vapor pressure equation was presented in reference [2]:

$$
\ln \left(\frac{P}{P_{t}}\right)=A_{1} X+A_{2} X^{2}+A_{3} X^{3}+A_{4} X(1-X)^{A_{5}}
$$

where $X=\left(1-T_{t} / T\right) /\left(1-T_{t} / T_{c}\right)$ and

$$
\begin{array}{ll}
A_{1}=7.89592346 & A_{5}=1.4327 \\
A_{2}=3.38765063 & P_{t}=2.52 \times 10^{-4} \mathrm{MN} / \mathrm{m}^{2} \\
A_{3}=-1.34590196 & T_{t}=53.4811 \mathrm{~K} \\
A_{4}=2.73138936 & T_{c}=144.31 \mathrm{~K} .
\end{array}
$$

\section{Saturated Liquid Densities}

The saturated liquid densities, $\rho_{l}$, were described in [2] with the argument $Z=1-T / T_{c}$, as

$$
\left(\frac{\rho_{l}-\rho_{c}}{\rho_{c}}\right)=B_{1} Z^{0.35}+\sum_{i=2}^{6} B_{i} Z^{i-1}
$$

where

$$
\begin{array}{ll}
B_{1}=1.81881076 & B_{5}=-1.01331503 \\
B_{2}=8.75236491 \times 10^{-1} & B_{6}=2.73840128 \times 10^{-1} \\
B_{3}=-8.50458910 \times 10^{-1} & \rho_{c}=15.10 \mathrm{~mol} / \mathrm{l} \\
B_{4}=1.37284761 & T_{c}=144.31 \mathrm{~K}
\end{array}
$$

\section{Saturated Vapor Density}

The saturated vapor densities, $\rho_{g}$, were reported by reference [2] as

$$
\ln \left(\frac{\rho_{g}}{\rho_{c}}\right)=C_{1}\left(\frac{Z}{Z-1}\right)+C_{2} Z^{0.35}+\sum_{i=3}^{7} C_{i} Z^{i-2}
$$

with the argument, $Z$, as given above. The coefficients are
$C_{1}=4.85547085$
$C_{3}=-1.88066900 \times 10^{-1}$
$C_{2}=-1.96015519$

$C_{5}=-2.29600897 \times 10^{1}$

$C_{7}=-4.30650270 \times 10^{1}$

$C_{6}=4.69524623 \times 10^{1}$

\section{The Melting Curve}

Straty and Prydz [3] represented the pressures along the solid-liquid melting curve as

$$
P=P_{t}+P_{0}\left[\left(\frac{T}{T_{c}}\right)^{c}-1\right]
$$

where

$$
\begin{aligned}
P_{0} & =249.975 \mathrm{MN} / \mathrm{m}^{2} \\
c & =2.1845,
\end{aligned}
$$

and the other variables as defined above.

\section{References}

[1] Straty, G. C., and Prydz, R., The vapor pressures of liquid fluorine, Advances in Cryogenic Engineering, Vol. 15, 36-41 (Plenum Press, New York, N.Y., 1970).

[2] Prydz, R., Straty, G. C., and Timmerhaus, K. D., Properties of fluorine along the vapor-liquid coexistence boundary, J. Chem. Phys. 53, No. 6, 2359-63 (1970).

[3] Straty, G. C., and Prydz, R., Melting curve and triple-point properties of fluorine, Physics Letters A, 31A, No. 6, 301-2 (1970).

[4] Straty, G. C., and Prydz, R., Fluorine compatible apparatus for accurate $P V T$ measurements, Rev. Sci. Instr. 41, No. 8, 1223-7 (1970).

[5] Bedford, R. E., Durieux, M., Muijlwijk, R., and Barber, C. R., Relationship between the International Practical Temperature Scale of 1968 and various "national temperature scales" in the range $13.81 \mathrm{~K}$ to $90.188 \mathrm{~K}$, Metrologia 5, 47 (1969).

[6] International Practical Temperature Scale of 1968, Adopted by the Comité International des Poids et Measures, Metrologia 5, 35 (1969).

[7] Burnett, E. S., Compressibility determinations without volume measurements, J. Appl. Mech., Trans ASME, 58, A136 (1936).

[8] Prydz, R., The Experimental PVT surface and corresponding thermodynamic properties of fluorine, Ph. D. Dissertation, University of Colorado, Boulder, Colorado (Aug. 1970).

[9] Prydz, R., and Goodwin, R. D., Specific heats, $C_{v}$, of compressed liquid and gaseous fluorine, J. Res. Nat. Bur. Stand. (U.S.), 74A (Phys. and Chem.), No. 5, 661-5 (1970).

[10] White, D., Hu, J-H., and Johnston, H. L., The intermolecular force constants of fluorine, J. Chem, Phys. 21, No. 7, 1149-52 (1953).

[11] Weber, L. A., P-V-T, thermodynamic and related properties of oxygen from the triple point to $300 \mathrm{~K}$ at pressures to 33 $\mathrm{MN} / \mathrm{m}^{2}$, J. Res. Nat. Bur. Stand. (U.S.), 74A (Phys. and Chem.), No. 1, 93-129 (1970).

[12] Gosman, A. L., McCarty, R. D., and Hust, J. G., Thermodynamic properties of argon from the triple point to $300 \mathrm{~K}$ at pressures to 1000 atmospheres, Nat. Std. Ref. Data Ser. - Nat. Bur. Stand. (U.S.), 27, W ashington, D.C. (Mar. 1969). 